\title{
Learning how to read? The value of lectures in the context of HE English Literature $^{1}$
}

\author{
Dr. Katarina Stenke \\ University of Greenwich, London, UK
}

\begin{abstract}
The increasing pace of change in today's teaching and learning, the challenging employability environments and the plethora of new technologies now at the disposal of teachers may seem to render obsolete the older teaching and learning methodologies. However, this reflective case study suggests that one of the oldest delivery modes of all, the lecture, remains a relevant and potentially valuable way of connecting with and supporting students in their learning, particularly in subjects where students are expected to read at length or otherwise to engage with extended and complex discursive modes. This case study offers evidence and arguments for reconsidering the role of lectures in teaching and learning higher education English Literature, taking as its evidence base levels 4 and 6 undergraduate English Literature modules delivered in 2017-18 and 2018-19 at the University of Greenwich. Rather than dismissing - as does much recent research - lectures as encouraging 'passive' learning, this reflective study proposes lecturing as a teaching methodology with unique potential.
\end{abstract}

\section{Introduction}

This reflective case study considers the value of lectures for teaching and learning in higher education (HE) English Literature, drawing on constructivism and social learning theory to re-think the function of lectures. The evidence base for the study consists of student and third-party observational feedback, along with the author's own teaching experience, on levels 4 and 6 English Literature modules delivered at the University of Greenwich in 20172019.

The argument made in this study is that traditional lectures should not be stigmatised as a medium encouraging passivity (Fry, 2015, p.64), ineffective for promoting thought (as cited in Bligh, 1972) or excessively teacher-led. Instead, this study supports the findings of recent research that attest to the value of lectures across HE (Light et al., 2009, p.105; French and Kennedy, 2017) and argues that, in the case of HE English Literature, this mode of teaching acts as a vital complement to other formats, one that can transform student affects in response to the subject matter and thus their attitudes towards it.

\section{History and context: teaching and learning literature at university}

\footnotetext{
1 I would like to extend my thanks to the tutors on the University of Greenwich PGCert in Higher Education, my participation in which was the initial prompt for the present case study; and to my Greenwich colleagues in English Literature, whose brilliant lectures constitute indisputable proof of the claims I make here. Particular thanks go to Ms Sally Alsford and Dr John Morton for their permission to quote excerpts from their unpublished reports (see Appendix).
} 
English Literature as a university subject dates from the early nineteenth century (Scholes, 1998; Graff, 1987), when lectures were the dominant formal learning activity (Scholes, op.cit.). This may be contrasted to subjects in the sciences, such as Chemistry, where practice-based learning, typically in laboratories, has been important since at least the eighteenth century. Despite many changes to syllabus design, especially in the last thirty years, lectures continue to be a major component of most HE English Literature programmes in the United Kingdom.

The function of English Literature lectures in today's learning and teaching environment needs to be understood in the context of disciplinary learning norms. It is a striking yet underacknowledged fact that the most important learning activity for a student of HE English Literature is the independent reading of literature (Chambers and Marshall, 2006, p.136). In any given week, literature undergraduates will be asked to read hundreds of pages of imaginative and critical writing - and to read them more intensively and with a different kind of attention than would peers following other humanities subjects. As well as understanding what is being said, literature students are expected to pay attention to how it's being said (Young, 2008, p.62).

What are the teaching and learning implications of the centrality of independent, long-form reading to the study of English Literature? At the most basic level, one might suggest, students enrolled at university on a programme based on the reading of literature can and should be expected to become habituated to reading at length and are therefore likely to engage better than average with monologic, long-form teaching formats such as lectures. Conversely, students who are being asked to develop the skills needed to read works of literature are likely to benefit from the experience of attending lectures, which may be said to consist of the oral and visual delivery of discourse and, as such, can themselves be considered a kind of text.

Given the correlation of the skill sets required and fostered by lectures and literary reading, the potential benefit of relying exclusively on conventional 'practice-based' group learning activities to support English Literature students is less than self-evident. Considering the attention span and independent development of comprehension required to read a Victorian novel, for example, it seems dangerous to assume that the best mode of learning for such students will, necessarily and/or exclusively, involve short-form group exercises in a frequently rotating variety of formats.

These claims seem to run counter not just to widely-disseminated studies arguing a deficit of student attention in lectures (Lloyd, 1968; see Wilson, 2007), but also to learning frameworks proposed by some of the most influential twentieth-century theories of teaching and learning. The next section considers constructivism and evaluates its usefulness in the specific context of University of Greenwich BA English Literature students, drawing on evidence from the author's seminar-based teaching and third-party feedback. After arguing that student-led, constructivist approaches as instantiated in seminar teaching, while undoubtedly valuable, are not sufficient in themselves for encouraging learning in English Literature, the study considers lectures as complements to seminar learning and discusses lectures given as part of level 4 and level 6 English Literature modules delivered in 2017/18 and $2018 / 19$ at the University of Greenwich. Subsequent to this discussion is a brief list of lecture strategies that the author has found to foster active learning and positive attitudes 
towards set reading among students. Finally, the study turns to social learning theory to reconceptualise the role of lectures in the discipline-specific context.

\section{Constructivism in seminar-based learning for English Literature levels 4-6}

At the University of Greenwich, English Literature students at levels 4, 5 and 6 are mostly taught via a combination of lectures and seminars. Each week, for a given module, they will attend a two-hour session consisting of a fifty-minute lecture followed by a fifty-minute seminar. For this session, they will be expected to have completed a reading assignment. In 2017/18, the author underwent two third-party observations (TPOs), one by a School mentor, Dr John Morton, of a lecture for the level 4 module 'The Canon' and one by a Postgraduate Certificate in Education (PGCE) in HE observer, Ms Sally Alsford, of a full twohour session for the level 6 'Literature of the Eighteenth-Century' module. Students on these modules also completed an end-of-year evaluative feedback form.

As in other humanities subjects, activity- and discussion-based seminars are key to the teaching of these modules, yet to be successful they need to fulfil certain criteria. From a constructivist point of view, learning is most likely to be successful when it is 'constructed', 'active', 'reflective', 'collaborative', 'enquiry-based' and 'evolving' (Papert, 1993). By these criteria, one of the crucial tasks for a teacher is to foster an environment where individuals feel 1) empowered to construct their learning actively, alongside and in 'collaboration' with their peers and 2) confident enough to engage in collective enquiry and reflection. For this, a minimum group consensus is required in order to allow conversations to develop.

Additionally, as far as group learning in English Literature is concerned, 'active' critical debate among students is impossible if there is no common basis of textual knowledge - i.e. what constructivists would term shared 'schemata' (Piaget 1950) - on which to apply the critical analyses and syntheses that are central to the practice of English Literature as a discipline.

One way of ensuring that everyone engages in a seminar is to plan activities that don't rely on prior module-specific knowledge. For example, the second TPO (January 2018), observed by PGCE in HE tutor Alsford, included an activity requiring students to (re-)read one of the two set scatological poems by the eighteenth-century writer Jonathan Swift, mapping the various body parts mentioned on a printed skeleton. The aim was to draw attention to the divergent manner in which Swift invokes the body in each of the respective works. Students responded well and Alsford, in her verbal feedback, commented favourably on the exercise, though she added that students would ideally have moved from structured analysis to open, student-led synthesis, a process that could have been stimulated by appropriate questions on my part. $^{2}$

That exercise used a format popular in the discipline, namely to provide short passages from the set text - which can be read and analysed in five to ten minutes - that the attendees close (re-)read before responding to questions or discussion points in groups. Such an activity thus effectively provides the textual and historical 'data' - and the 'schemata' - in seminar. This provides a basis of shared knowledge and allows meaningfully evidenced

\footnotetext{
${ }^{2}$ Details of this TPO report, with relevant excerpts, are given in the Appendix.
} 
arguments to develop, but the trade-off is that solitary (re-)reading takes up time that could be used for developing critical and analytical skills in group settings.

Furthermore, as Alsford recognized, the wider contexts of a given passage, and the higher levels of the Bloom taxonomy, tend to get left to one side. Lastly, not just in this instance but also in my wider experience, generally less-engaged students tend to remain so. Thus in this kind of group activity, the disparity between those who have completed the set reading and those who haven't persists. The former are able and often keen to contextualise the short passage with reference to the set reading as a whole, and tend to feel frustrated if they are in the minority. By contrast, those who haven't completed the preparatory reading tend to fall silent and dis-engage once discussion moves to incorporate the whole text. In short, where a sizeable proportion of students have not completed the preparatory reading, the potential 'constructive' outcomes of seminar-based learning remain limited regardless of in-seminar strategies designed to level the playing field.

One of the key challenges in HE English Literature teaching is therefore to find ways of supporting and encouraging students to complete the required reading. Based on informal polls among my own students, I estimate that sixty per cent of students who attend a level 4 or 5 core seminar will regularly admit to not having completed the set reading - this, despite the fact that reading is carefully paced to be manageable for students and is only slightly more substantial than the volume of reading expected of A-level English Literature students.

\section{Analysis: lectures as complements to seminars}

Considering these challenges, and on the evidence of the present case study, it seems likely that a conventional lecture - acting as an advertisement for and introduction to the set text, habituating students to academic and literary discourse and modelling best practice in reading attention and academic argument - has the potential to foster positive attitudes to learning materials, get students reading and encourage active learning, both in seminars and during independent study.

This, I propose, works in several ways. Lectures, at their most basic, can ensure a minimum cross-group level of contextual/textual knowledge in advance of seminars, where, as we have seen, constructive learning relies on students' having a shared basis of textual and contextual knowledge on which to practise critical and other skills.

Furthermore, where students are initially unwilling to engage in 'flipped' learning outside the classroom (Steen-Utheim and Foldnes, 2018), I have found that successful lectures can help to enthuse as well as inform, so that learners leave the classroom more confident and engaged and therefore more likely to tackle future preparatory reading assignments. The lectures delivered for the English Literature BA are frequently mentioned in the positive feedback column of student evaluation surveys as engaging and informative, views supported by third-party observation reports. ${ }^{3}$

In both of the TPOs, the observers commented on the evident engagement and attention of the students and the positive relationship between students and lecturer; they also praised

\footnotetext{
${ }^{3}$ These quotations are from the aforementioned TPO report by John Morton (2017) and from University of Greenwich student evaluation surveys from the modules under discussion. See Appendix for details of and the relevant excerpts from these sources.
} 
the interest of the materials - this is also typical of lectures by colleagues. ${ }^{4}$ Additionally, in several of my first-year core module seminars, students who verbally admitted to not having read the text added that attending the lecture motivated and equipped them to tackle the text in advance of the following week's session.

This evidence emphasises the fact that lectures don't just - or even primarily - convey information. They have the potential to offer a live demonstration of how to read and of how the abstruse material of a literary work can be transformed into personalised meaning; they also advertise set texts as worth reading. Consequently, they can transform students' affects in response to a text, enthusing them to attempt extensive independent reading.

Drawing on the evidence discussed in this analysis and identifying common techniques from positively-evaluated lectures in my subject area, I suggest that lecture strategies for enthusing English Literature students and fostering independent reading of literary texts might include:

- explicitly sharing personal enthusiasm for, and enjoyment of, reading in general and of the set text in particular, while allowing students the space to articulate their own responses;

- clearly articulating the benefits to students of reading and engaging critically with a given text; (These benefits might be learning-specific - e.g. 'this text is a great example of how novels can use point of view to shape reader sympathies'; 'reading this Elizabethan sonnet will be helpful to you in future reading assignments, because its rhetorical and metrical strategies are imitated, developed and parodied in so many of the poems you'll be reading over the next few years' - or they might be at the level of enjoyment or personal meaning - 'although this book initially seems rather serious in tone, later chapters are very funny; if you get as far as chapter 5 you'll be rewarded with a comical set piece on...'; 'if you've ever experienced $x$ you may find this work really speaks to you, because...')

- taking time to 'narrativise' the lecture - for instance by announcing the kind of critical argument that will be made across (a section of) it or the kind of historical narrative that will be traced and by reminding students that these are practices they are expected to demonstrate in assessments; (This adds a sense of purpose to the sequence of materials and gives the students a way of connecting to the lecture beyond the interest/relevance of information provided.)

- reflecting in-lecture on the lecturer's own readings of set texts - especially difficulties they might have experienced as a reader before beginning to enjoy a challenging work - or the different ways they might have interpreted a text before deciding on how to present it in the lecture; (The aim here is communicate to students that it is possible to learn to enjoy reading a work that initially seems challenging. It can also be a way of reminding students that lectures not only present information but are also the outcomes of reading processes and critical analyses - skills that they themselves are developing.)

\footnotetext{
${ }^{4}$ See Appendix.
} 
- $\quad$ regularly noting the diversity of critical views that exist of a given work;

(This can help activate students' sense of agency as readers, by showing them that there are many ways of responding to a text and that these freedoms are available to them as readers.)

- $\quad$ pinpointing connections between the - often historical and contextually remote - texts and students' existing knowledge, experience and interests, such as current events, shared life experiences, cultural practices etc; (This offers a shared 'schemata' within which both lecturer and students are able to connect to a text and engage meaningfully with it.)

- $\quad$ using in-lecture surveys or questions (via Mentimeter or similar software) to help create collective 'schemata', foster inclusivity and enhance engagement.

In implementing such strategies, it would be crucial to ensure constructive alignment between these elements of the lecture and the seminars to follow.

\section{Re-theorising English Literature lectures}

Bearing the above in mind, how might we make use of established teaching and learning theory to understand discipline-specific learning parameters as well as how lectures operate, not necessarily in general HE or humanities contexts, but specifically for English Literature?

One approach would be to challenge the hidden assumptions in such theories that misrecognise the nature of reading and of lectures as a teaching format and to re-tool the theory so that it can help us optimise our lectures. Theories that at first sight seem inapplicable to literature studies and to contra-indicate lectures might thus allow us to reimagine their function and effects.

Take, for instance, social learning. One way to apply this theory to lectures is to argue that in a diverse and disaggregated student body, lectures help establish what Etienne Wenger terms 'a community of practice', in which subsequent active and social learning can develop (Wenger, 1998; Wenger, McDermott and Synder, 2002). Yet many aspects of social learning theory militate against such a format. Just as for Papert, who argues that 'the construction that takes place in the head' often happens especially felicitously when it is supported by construction of a more public sort 'in the world' (Papert, 1993, p.142), social learning theory prioritises world over mind. Thus, for Wenger, distraction-free, classroom-based (Wenger, 1998, p.3) learning is suboptimal, because natural learning and the application of what we learn take place in social situations and situations in the 'outside world' (ibid.) Teachers should therefore avoid artificially separating learning from 'the world' (ibid.), and instead learn from how learning happens in society, with techniques that encourage practice and active engagement of learners.

But where does that leave reading, a practice which after all relies on an act of mental concentration which temporarily neglects 'the world' in favour of the text? Must we assume that reading and learning are incompatible? If so, how do we learn how to read? And does this mean that the lecture - where, supposedly, the student body silently attends to the lecturer (itself a poor approximation of what actually happens in lectures) - must also be regarded as divorced from community and that, therefore, whatever it offers will fail to transfer to 'the outside world' (whatever or wherever that may be)? 
In order to resolve these apparent impasses, it's worth thinking carefully about that boundary Wenger invokes, between 'outside world' and 'classroom'. Following the work of critical theorists in the late-twentieth century - and especially in the still-unfolding aftermath of the electronic revolution - we may wish to be wary of such neat borders. Firstly, the hermetically sealed classroom or lecture hall or student room needs to be recognised as a straw man that never existed, since work by thinkers as diverse as Michel Foucault and Bruno Latour has made clear that social hierarchies, practices, dynamics and behaviours permeate inescapably into even the most sterile institutional and domestic environments (Foucault, 1991; Latour, 2005); the theories of Freud and those post-structuralist thinkers who have developed his work further suggest that the very subject (whether teacher or learner) is, to an extent, a social world in itself, a shifting amalgam of competing impulses and discourses constituted out of a wider (social) world of language and action (Lacan, 2001). Secondly, once we introduce technology into the learning space, the border between inside and out becomes still more uncertain and permeable. Perhaps the lecture hall and the student reading room are not so un- or anti-social after all.

With these qualifications in mind, a helpful term found elsewhere in social learning theory is that of learning 'contexts'. In her introduction to Understanding Practice, the anthropologist Jean Lave writes that

if context is viewed as a social world constituted in relation with persons acting, both context and activity seem inescapably flexible and changing. And thus characterized, changing participation and understanding in practice - the problem of learning cannot help but become central as well (Lave, 1993, p.5)

Social worlds are made up of people acting and relating in particular, ever-changing situations. As such, learning (defined as a process that 'changes' the way people act and relate) must also be socially 'situated'.

How might that work for teaching and learning English Literature? If we now recognise that 'social worlds' may include those constituted by electronic social media, it's worth remembering similarly that discourse itself - in printed or electronic form - should also be considered as a kind of social world, 'a multi-dimensional space', where, as Roland Barthes has argued, 'a variety of writings... blend and clash' (Barthes, 2009, p.146). When students are enabled to enter the world of a literary text, they don't find there an arid, authoritarian voice, but a teeming polyphony. The difficulty is learning to recognise, comprehend and then interact with that polyphonic discourse as a special type of social setting, to acquire and practise a set of skills relating to knowledge-acquisition and interpretation in that situation.

\section{Conclusion}

With these demands in mind and recognising that lecture-attendance is not - any more than is solitary reading - an 'unsocial' or 'unworldly' experience, lectures may perhaps best be seen as offering a valuable bridge between student and text, shaping communities of practice by creating an intermediate social space. In this way, they can both stimulate critical thinking and promote reflective engagement.

Lectures, seen through this modified social-learning lens, share both the apparent monovocality and density of a literary text and the interpersonal setting and informal discourse 
which we normally regard as typical of the 'outside world'. The interpersonal nature of the lecture becomes clearer still if we see live lectures as social events, where both lecturer and students may be considered as actors. Students in such a setting continuously perform their attention and engagement (or lack thereof) and their continuing professionalisation, feeding this back to both lecturer and peers and thereby inhabiting a posture of scholarship in ways that can shape their sense of identity and thus their ability to act as scholarly learners. This potential for lecturers to be subtly but powerfully interactive is intensified further still if student-engagement applications such as Mentimeter are used to foster a sense of real-time community and investment and, by that means, to enrich the 'schemata' acquired by students working separately.

Moreover, one of the things that a lecture might achieve is to perform the process of reading itself, by means of narrative structures that dramatise the readerly progress from unfamiliarity to understanding. In this sense, then, understood as community-building performance, lectures offer the opportunity both to communicate ideas, facts and codes that may be deployed as a shared resource by the student group and to introduce students to unfamiliar 'situations'. Lectures, in short, might constitute an experiential process that would successfully and meaningfully shape responses, transform attitudes, and, thereby, 'change behaviours' (Lave, op.cit.).

This potential naturally relies on lectures' having been carefully designed to achieve these different outcomes. In order to provide a more systematic study of strategies for achieving these outcomes, the author aims to conduct a longitudinal study to trial design principles and monitor outcomes.

\section{Reference list}

Barthes, R. (1977) 'Death of the Author.' In: Image, Music, Text. New York: Polity Press. ISBN: 9780006861355.

Biggs, J. and Tang, C. (2009) Teaching for Quality Learning at University. $3^{\text {rd }}$ edn. Maidenhead: Open University Press. ISBN: 9780335201716.

Bligh, D. (1998) What's the Use of Lectures? $5^{\text {th }}$ edn. Exeter: Intellect. ISBN: 9781871516791.

Bloom, B. (1956) Taxonomy of Educational Objectives. Handbook I: The Cognitive Domain. New York, NY: David Mc Kay. ISBN: 9780582323865.

Brown, S. and Race, P. (2002) Lecturing: A Practical Guide. Location: Kogan Page. ISBN: 9780749436711.

Chambers, E. and Marshall, G. (2006) Teaching and Learning English Literature. London: Sage Publications. ISBN: 9780761941729.

Fry, H., Ketteridge, S., Marshall, S. (2015) A Handbook for Teaching and Learning in Higher Education. $4^{\text {th }}$ edn. Abingdon: Routledge. ISBN: 9780415709965. 
French, S. and Kennedy, G. (2017) 'Reassessing the Value of University Lectures.' Teaching in Higher Education, 22(6), 639-654. Available at:

https://doi.org/10.1080/13562517.2016.1273213 (Accessed: 12 December 2019).

Foucault, M. (1991) Discipline and Punish: The Birth of the Prison. Harmondsworth:

Penguin. ISBN: 9780140137224.

Graff, G. (1987) Professing Literature: An Institutional History. Chicago: University of Chicago Press. ISBN: 9780226305592

Lacan, J. (2001) Écrits: A Selection. Abingdon, Oxon: Routledge. ISBN: 9780415253925.

Latour, B. (2005) Reassembling the Social: An Introduction to Actor-Network-Theory. Oxford: Oxford University Press. ISBN: 9780199256044.

Lave, J. (1993) 'The Practice of Learning.' In: Chaiklin, S. and Lave, J. (eds.), Understanding Practice: Perspectives on Activity and Context. Cambridge: Cambridge University Press, 332. ISBN 9780511625510. Available at: https://doi.org/10.1017/CBO9780511625510. (Accessed: 13 December 2019).

Light, G., Cox, R. and Calkins, S. (2009) Learning and Teaching in Hlgher Education: The Reflective Professional. London: Sage. ISBN: 9781446243763.

Lloyd, D.H. (1968) 'A Concept of Improvement of Learning Response in the Taught Lesson.' Visual Education, October, 23-25.

Papert, S. (1993) The Children's Machine: Rethinking Schools in the Age of the Computer. New York: Basic Books. ISBN: 9780465018307.

Piaget, J. (1950, repr. 2001) The Pyschology of Intelligence, trans.d Piercy M. and Berlyne, E. London: Routledge and Kegan Paul. ISBN: 9780415254014.

Race, P. (2007) The Lecturer's Toolkit. $3^{\text {rd }}$ edn. London: Routledge. ISBN: 978041540383.

Scholes, R. (1998) The Rise and Fall of English: Reconstructing English as a Discipline. New Haven: Yale University Press. ISBN: 9780300080841.

Steen-Utheim, A.T. and Foldnes, N. (2018) 'A Qualitative Investigation of Student Engagement in a Flipped Classroom.' Teaching in Higher Education, 23(3), 307-324. Available at: https://doi.org/10.1080/13562517.2017.1379481(Accessed: 12 December 2019).

Wenger, E. (1998) Communities of Practice: Learning, Meaning, and Identity. Cambridge: Cambridge University Press. ISBN: 9789521663632.

Wenger, E., McDermott, R. and Synder, W. (2002) Cultivating Communities of Practice: a Guide to Managing Knowledge. Boston, MA: Harvard Business School Press. ISBN:

9781422131107. 
Wilson, K., Korn, J. (2007) 'Attention During Lectures: Beyond Ten Minutes', Teaching in Psychology, 34 (2), 85-89. Available at: https://doi.org/10.1080/00986280701291291 (Accessed: 12 December 2019). 


\section{Appendix}

The claims of this case study refer to data from unpublished sources. See below for details

1) Sally Alsford, third party observation (TPO) report on K. Stenke, 2-hour combined lecture and seminar for University of Greenwich Level 6 module 'School for Scandal: Literature of the Long Eighteenth Century', undertaken in January 2018.

This observation was one of the required elements of a PGCert in Higher Education at the University of Greenwich, undertaken by the author. Ms Sally Alsford was at that time the programme director as well as one of the programme tutors.

Excerpts relevant to this study:

'[The students] were clearly listening and learning in the more teacher-led/lecture parts of the session'.

'[The observee was] very good at engaging students'.

'I really liked [the observee's] use of images, and the lists/skeleton activity, and students responded well to this, also to working in pairs where they were clearly learning collaboratively'.

'I think [the seminar] should perhaps be stretching them further to develop their critical evaluation and analysis (especially at level 6), eliciting analytical points and examples from them, asking them more questions to help them develop their analysis and argument.'

2) John Morton, third party observation report on K. Stenke, 1-hour lecture for University of Greenwich Level 4 module 'The Canon: A Short History of Western Literature', undertaken in December 2017.

This observation was one of the required elements of a PGCert in Higher Education at the University of Greenwich, undertaken by the author. Dr John Morton is Associate Professor in English Literature at the University of Greenwich. He undertook the observation in the capacity of PGCert mentor to the author.

Excerpts relevant to this study:

'The communication of ideas was clear, informal, and precise. Students were asked questions (and not given answers) on knowledge [...] and [on their reading] response [...] which encouraged active learning and engagement.'

'There were [...] links back to other texts and topics from the course, encouraging a community of knowledge.' 
'Students clearly felt comfortable and there were some nice nods to their own lives [...]. The introduction through shared knowledge helped to build confidence.'

3) Feedback from student evaluation surveys on level 4 English Literature module 'The Canon: A Short History of Western Literature', University of Greenwich, 2017-2018 and level 6 English Literature module 'School for Scandal: Literature of the Long Eighteenth Century', 2017-18 and 2018-19. The survey data are collected and compiled via EvaSys (https://evasys.co.uk/)

Excerpts relevant to this study:

- 'the lecture[r]s were great' ('The Canon', 2017-18)

- "I like the format of lectures where a lecture is given and then activities are discussed in groups and later discussed as a class" ('School for Scandal', 2017-18)

- [the author] 'deliver[ed] the lecture so that you understand everything' ('School for Scandal', 2018-19) 